\title{
Realgar-mediated growth inhibition on HaCaT human keratinocytes is associated with induction of apoptosis
}

\author{
WAI-PUI TSE ${ }^{1}$, CHRISTOPHER H.K. CHENG ${ }^{2}$, CHUN-TAO CHE ${ }^{1}$, \\ MING ZHAO ${ }^{1}$, RUI-QIANG FAN ${ }^{3}$ and ZHI-XIU LIN ${ }^{1}$ \\ ${ }^{1}$ School of Chinese Medicine, Faculty of Science, ${ }^{2}$ Department of Biochemistry, Faculty of Medicine, \\ The Chinese University of Hong Kong, Shatin, N. T., Hong Kong; ${ }^{3}$ Department of Dermatology, \\ Guangdong Provincial Hospital of Chinese Medicine, Guangzhou, P.R. China
}

Received February 9, 2009; Accepted April 6, 2009

DOI: 10.3892/ijmm_00000222

\begin{abstract}
Traditional Chinese medicine has long been used to treat a variety of ailments including skin diseases. Our previous study has revealed the ethanolic extract of realgar, a common ingredient used in psoriasis treatment in Chinese medicine, to possess potent anti-proliferative action on cultured HaCaT cells of human keratinocyte origin. In the present study, the mechanisms of action of the observed growth inhibitory action of realgar were investigated. Several bioassay methods were employed to elucidate whether cellular apoptosis is involved in the realgar-induced growth inhibition of the skin cells. Morphologically, nuclear condensation and DNA fragmentation were observed when HaCaT cells were exposed to the realgar extract. DNA fragmentation induced by the treatment of realgar was also evident as detected by gel electrophoresis and the TUNEL method. Cell cycle analysis by propidium iodide (PI) staining demonstrated the appearance of sub-G1 peak and cell cycle arrest at the G1 phase upon realgar treatment. Quantitative analysis by annexin V-PI staining revealed that the realgar-induced apoptotic event was dose-dependent. Furthermore, realgar was able to activate caspase-3 expression when examined by Western blot analysis. Our experimental data unambiguously confirm that induction of cellular apoptosis is mainly responsible for the observed growth inhibition brought about by realgar on the HaCaT keratinocytes, and this finding helps place the traditional use of this mineral for psoriasis treatment on a scientific footing.
\end{abstract}

\section{Introduction}

Psoriasis is a chronic inflammatory skin disease that affects approximately $2 \%$ of the population worldwide $(1,2)$. Although

Correspondence to: Dr Zhi-Xiu Lin, School of Chinese Medicine, Faculty of Science, The Chinese University of Hong Kong, Shatin, N. T., Hong Kong, P.R. China

E-mail: linzx@cuhk.edu.hk

Key words: realgar, psoriasis, $\mathrm{HaCaT}$ keratinocytes, apoptosis, anti-proliferation many therapeutic modalities such as topical application, phototherapy and systemic treatment are currently available for treating psoriasis, the common problems of inadequate efficacy, drug tolerance and the often associated adverse effects render psoriasis still an unmet medical need to date (1). Patients with psoriasis often turn to alternative and complementary treatment. In China for instance, psoriasis is often treated with a variety of oral or topical formulations of Chinese medicine today. Many of these anti-psoriatic preparations employ arsenic-containing minerals such as realgar (the main ingredient is $\mathrm{As}_{2} \mathrm{~S}_{2}$ ) or orpiment (the main ingredient is $\mathrm{As}_{2} \mathrm{~S}_{3}$ ). In fact, the use of realgar in Chinese medicine is not confined to psoriasis alone. For example, more than 20 oral preparations containing realgar are included in the Chinese Pharmacopoeia (3) for the treatment of a broad variety of diseases ranging from common cold, skin conditions to stroke and tumour. In our earlier screening programme in which 60 commonly prescribed Chinese medicinal materials for treating psoriasis were investigated for their potential anti-psoriatic action on cultured $\mathrm{HaCaT}$ keratinocytes as a psoriasis-relevant model, realgar was found to be a potent anti-proliferative agent on the cells (4). The finding provides experimental evidence to support the use of realgar as an important ingredient in Chinese medicine practice for psoriasis treatment. However, the underlying cellular and molecular mechanisms of action for the observed keratinocyte growth inhibition remain hitherto unexplored. As part of our continuing effort to develop efficacious antipsoriatic pharmaceutical treatment from traditional remedies, we undertook further experiments in an attempt to elucidate the action mechanism regarding the anti-psoriatic action of realgar. This report provides experimental evidence to indicate that induction of cellular apoptosis is the major mechanism of action responsible for the realgar-mediated anti-proliferation on $\mathrm{HaCaT}$ human keratinocytes.

\section{Materials and methods}

Chemicals and reagents. Realgar in fine powder form was purchased from Hung Kei Herbal Company, Hong Kong. Its identity was confirmed by comparing with the authenticated specimen stored at the Herbarium of the School of Chinese 
Medicine, The Chinese University of Hong Kong, where a voucher herbarium specimen of the material used in this study has been deposited. For preparation of realgar extract, we used $80 \%$ aqueous ethanol as the extracting solvent since this method was employed in our previous study (4). Briefly, $100 \mathrm{ml} 80 \%$ aqueous ethanol was added into $30 \mathrm{~g}$ of realgar powder and sonicated in an ultrasonic bath at $50^{\circ} \mathrm{C}$ for $30 \mathrm{~min}$. The extract was filtered and the residue was further extracted twice with $80 \%$ aqueous ethanol as before. All three filtrates were combined, and then concentrated in a rotary evaporator under negative pressure, and finally dried in blowing air. The extract yield was calculated $(0.9 \%)$ and the resultant extract stored at $-20^{\circ} \mathrm{C}$ for subsequent bioassay testing.

Unless otherwise specified, other chemicals and reagents used in the study were of analytical grade obtained from Sigma-Aldrich (St. Louis, MO, USA). Dulbecco's modified Eagle's medium (DMEM), fetal calf serum (FCS) and trypsinEDTA (1X) were purchased from Invitrogen (Carlsbad, CA, USA).

General cell culture. HaCaT cell line, which is a spontaneously immortalized line of human epidermal keratinocytes that exhibits normal differentiation (5) and has been extensively used as an in vitro model for the studies of psoriasis (6-8), was obtained from the China Centre for Type Culture Collection, Wuhan, Hubei Province, China. The HaCaT cells were routinely maintained in DMEM supplemented with $10 \% \mathrm{FCS}, 10 \mu \mathrm{g} / \mathrm{ml}$ streptomycin and $10 \mathrm{U} / \mathrm{ml}$ penicillin and incubated at $37^{\circ} \mathrm{C}$ in a $5 \% \mathrm{CO}_{2}, 95 \%$ air humidified atmosphere. All cell culture experiments were carried out when the culture was approximately $60-90 \%$ confluent.

MTT assay for HaCaT cell growth. The realgar extract was reconstituted in phosphate-buffered saline (PBS) followed by sterilization by filtration $(0.2-\mu \mathrm{m}$ pore size filter; Corning Inc., Corning, NY, USA). The realgar extract together with HaCaT cells were cultured in 96-well plates, with each well containing $2 \times 10^{4}$ cells in $200 \mu 1$ DMEM. The final concentrations of the realgar extract ranged from 31.2 to $0.24 \mu \mathrm{g} / \mathrm{ml}$ by serial doubling dilutions. The incubation time was set for 3, 6, 12, 24, 48 and $72 \mathrm{~h}$. The 3-(4,5-dimethylthiazol-2-yl)2,5-diphenyltetrazolium bromide (MTT) assay was carried out to determine the cell viability as described previously (4). Briefly, MTT was added to the wells at a final concentration of $0.5 \mathrm{mg} / \mathrm{ml}$ and incubated at $37^{\circ} \mathrm{C}$ for $2 \mathrm{~h}$. The medium was then carefully removed from the wells and replaced with $100 \mu 1$ DMSO. The absorbance of the dissolved formazan dye was recorded at $540 \mathrm{~nm}$ using a microplate spectrophotometer (FLUOstar Optima; BMG Labtech, Durham, NC, USA).

Fluorescent staining of HaCaT cells for morphological evaluation. The morphological evaluation of realgar-treated $\mathrm{HaCaT}$ cells was performed using the previously described methods (9). Briefly, approximately $7.5 \times 10^{5} /$ well HaCaT cells were seeded in 6-well plates. The cells were treated with $10 \mu \mathrm{g} / \mathrm{ml}$ realgar extract for $48 \mathrm{~h}$. After the incubation, the plate was centrifuged at 3,000 x g for $10 \mathrm{~min}$ and the wells were then gently washed with PBS to remove the cell debris, and the cells remaining attached were fixed in $4 \%$ parafor- maldehyde for $30 \mathrm{~min}$. Subsequently, the fixed cells were stained with $20 \mu \mathrm{g} / \mathrm{ml}$ Hoechst 33342 (Molecular Probes, CA, USA) for $15 \mathrm{~min}$ at room temperature in the dark. Morphological changes in the cells treated with realgar was evaluated using an inverted fluorescent microscope (Olympus, Tokyo, Japan).

DNA fragmentation assay. A million HaCaT cells were seeded in 100-mm plates and exposed to realgar extract at 2, $5,10,15$ and $20 \mu \mathrm{g} / \mathrm{ml}$ for 24,48 and $72 \mathrm{~h}$. After harvest by trypsinization, the cells were lysed in $200 \mu 1$ of DNA lysis buffer at $37^{\circ} \mathrm{C}$ for $15 \mathrm{~min}$. The supernatant was sequentially incubated with $10 \mu \mathrm{l}$ RNase $(4 \mathrm{mg} / \mathrm{ml})$ and then with $20 \mu \mathrm{l}$ proteinase $\mathrm{K}(1.5 \mu \mathrm{g} / \mathrm{ml})$ at $56^{\circ} \mathrm{C}$ for $1.5 \mathrm{~h}$. The DNA of the cells was then precipitated with sodium acetate and centrifuged at $20,000 \mathrm{x}$ g for $30 \mathrm{~min}$. Finally, $30 \mu \mathrm{l}$ of Tris-EDTA buffer was added to the sample and incubated at $37^{\circ} \mathrm{C}$ for $30 \mathrm{~min}$. To analyze the fragmented DNA, $10 \mu 1$ of the extracted cellular DNA was electrophoresed on a $1.5 \%$ agarose gel, and the DNA ladders in the gels were visualized under UV light after staining with ethidium bromide.

TUNEL assay. To further analyze DNA fragmentation, the TUNEL assay, in which DNA strand breaks can be detected by enzymatic labeling of the free 3 '-OH terminal with modified nucleotides, was employed using methods described previously $(10,11)$. In brief, approximately $7.5 \times 10^{5} /$ well $\mathrm{HaCaT}$ cells were seeded on a 6 -well plate and exposed to realgar extract at $8 \mu \mathrm{g} / \mathrm{ml}$ for $48 \mathrm{~h}$ at $37^{\circ} \mathrm{C}$. At the end of incubation, the cells were fixed in $2 \%$ paraformaldehyde for $1 \mathrm{~h}$ and permeabilised with $0.1 \%$ Triton $\mathrm{X}-100$ at $4^{\circ} \mathrm{C}$ for $2 \mathrm{~min}$, followed by incubation at $37^{\circ} \mathrm{C}$ in the dark for $1 \mathrm{~h}$ with $50 \mu 1$ terminal deoxynucleotidyl transferase biotindUTP nick end labeling (TUNEL) reaction mixture provided with the In Situ Cell Death Detection kit (Roche Applied Science, PA, USA). Finally, the cells were re-suspended in $0.5 \mathrm{ml}$ PBS and analyzed by FACSort flow cytometry (Becton-Dickinson, NJ, USA).

Cell cycle analysis with propidium iodide (PI) staining. Approximately $7.5 \times 10^{5} \mathrm{HaCaT}$ cells seeded on 6-well plates were exposed to realgar extract at 2, 5, 10 and $20 \mu \mathrm{g} / \mathrm{ml}$ for 24,48 or $72 \mathrm{~h}$. After trypsinization, the cells were fixed in $70 \%$ ethanol at $4^{\circ} \mathrm{C}$ overnight, and were then re-suspended in $10 \mu \mathrm{l}$ PI solution $(2 \mathrm{mg} / \mathrm{ml})$ with $50 \mu 1 \mathrm{RNAase}(10 \mathrm{mg} / \mathrm{ml})$ and incubated in the dark at $37^{\circ} \mathrm{C}$ for $30 \mathrm{~min}$. They were then subjected to DNA content analysis using a FACSort flow cytometer (Becton-Dickinson) in which the 'CellQuest' programme was used to analyze the results. Different phases of the cell cycle were assessed by collecting the signal at channel FL2-A. The percentage of the cell population at a particular phase was estimated by ModFit LT for Mac V.3.0 computer programme (Verity Software House, Topsham, ME, USA) according to the methods described previously $(12,13)$.

Quantitative analysis of apoptotic cells by annexin V-PI staining. Approximately $7.5 \times 10^{5} \mathrm{HaCaT}$ cells were seeded on 6-well plates and incubated with realgar extract at 2, 5, 10 and $20 \mu \mathrm{g} / \mathrm{ml}$ for 24,48 or $72 \mathrm{~h}$. After trypsinization, the cells were pooled together and stained concomitantly with 


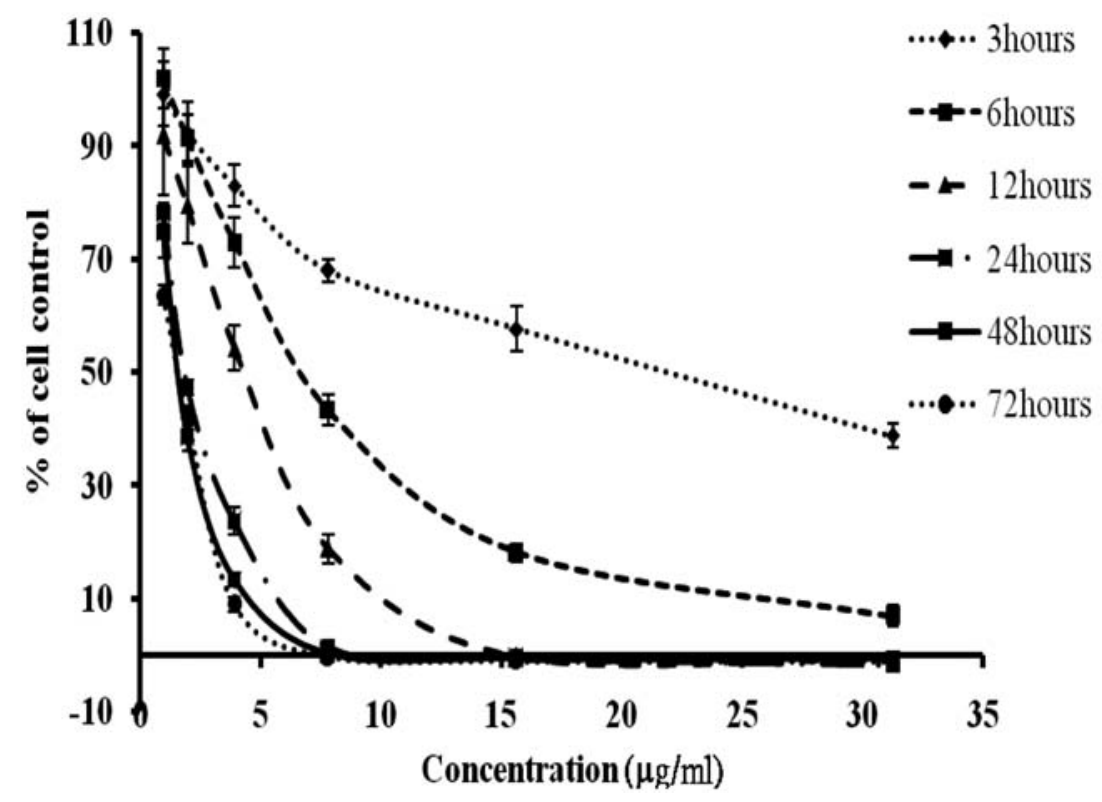

Figure 1. Growth inhibitory action of realgar extract on cultured HaCaT cells. The HaCaT cells were treated with various concentrations of realgar extract and incubated for different time periods followed by MTT assay. The $\mathrm{IC}_{50}$ values at 3, 6, 12, 24, 48 and $72 \mathrm{~h}$ time points were determined as $22.0,6.9,4.4,1.9,1.6$ and $1.6 \mu \mathrm{g} / \mathrm{ml}$, respectively using a GraphPad Prism 3.0 computer programme. The values shown are the mean $\pm \mathrm{SEM}$, with $\mathrm{n}=6$.

annexin V and PI. The annexin V used was a chimeric recombinant protein produced by fusing green fluorescent protein (GFP) to the N-terminus of annexin V (14). The stained cells were subsequently analyzed by flow cytometry (Becton-Dickinson). The signal was detected by FL1 and FL3 channels, and quadrant markers were set on dotplots of unstained and stained cells.

Western blot analysis of caspase-3. A million cells seeded on each 100-mm plate were exposed to realgar extract at 2, 5, 10,15 and $20 \mu \mathrm{g} / \mathrm{ml}$ for 24,48 and $72 \mathrm{~h}$. The cells removed from the culture plates by scraping were lysed with lysis buffer for $3 \mathrm{~h}$. The resultant lysates were boiled for $10 \mathrm{~min}$. The supernatant was collected and stored at $-20^{\circ} \mathrm{C}$. The protein concentrations were measured with the Bicinchoninic acid protein assay kit. Equal amounts of protein were resolved by sodium dodecyl sulfate-polyacrylamide gel electrophoresis (SDS-PAGE) on a $15 \%$ gel. Separated proteins were then electro-transferred onto a PVDF membrane (Bio-Rad, Hercules, CA, USA) which was then blocked with $10 \%$ nonfat milk. The membrane was then sequentially probed with the primary anti-caspase-3 antibody (Calbiochem, La Jolla, CA, USA) and the secondary peroxidase-conjugated goat anti-rabbit IgG antibody (Santa Cruz Biotechnology, CA, USA). The immunoreactive bands were visualized with an ECL Western blotting detection kit (Amersham Life Sciences, Sydney, Australia) on light sensitive film (AGFA, Mortsel, Belgium). Rainbow molecular weight markers were used as size markers for the determination of protein size.

Statistical analysis. Data are expressed as mean values \pm SEM. Statistical comparisons between realgar extract treatment and control were carried out using one-way analysis of variance (ANOVA), followed by post-hoc Dunnett's test using the non-treatment as the control group on the SPSS for Windows (version 14.0). Differences were considered significant at $\mathrm{p}<0.05$ and were denoted as ${ }^{*} \mathrm{P}<0.05,{ }^{* *} \mathrm{P}<0.01$ and ${ }^{* * *} \mathrm{P}<0.001$

\section{Results}

Inhibitory effect of realgar on the growth of HaCaT cells. Based on our previous findings that realgar extract possesses potent keratinocyte growth inhibition, in the present study we further investigated the concentration- and time-dependent patterns of this anti-proliferative effect. The growth inhibitory action of realgar on $\mathrm{HaCaT}$ keratinocytes as determined by MTT assay is shown in Fig. 1. It is evident that realgar extract exerted potent growth inhibitory effect on the HaCaT keratinocytes in a concentration- and time-dependent manner. The $\mathrm{IC}_{50}$ values of realgar on the growth of HaCaT cells when incubated for $3,6,12,24,48$ and $72 \mathrm{~h}$ were 22.0, 6.9, $4.4,1.9,1.6$ and $1.6 \mu \mathrm{g} / \mathrm{ml}$, respectively. These results in general agree with our previous findings regarding the antiproliferative effect of realgar extract on $\mathrm{HaCaT}$ keratinocytes in culture (4).

Realgar-induced alteration of cellular morphology. The potent growth inhibitory action of realgar warrants further study into the underlying mechanisms for the observed biological effect. As cellular necrosis and apoptosis are the two main pathways leading to cell growth inhibition, we have therefore focused our investigation on whether cellular apoptosis is involved in the realgar-mediated keratinocyte growth inhibition using a number of bioassay methods.

After exposure to $10 \mu \mathrm{g} / \mathrm{ml}$ realgar for $48 \mathrm{~h}$, a greater number of HaCaT cells showed detachment from the culture plate and displayed fewer intercellular connections when compared to the non-treated control (Fig. 2a and b). In addition, the Hoechst-stained realgar-treated HaCaT keratinocytes appeared to be shrunken and exhibited typical apoptotic morphology characterized by chromatin conden- 


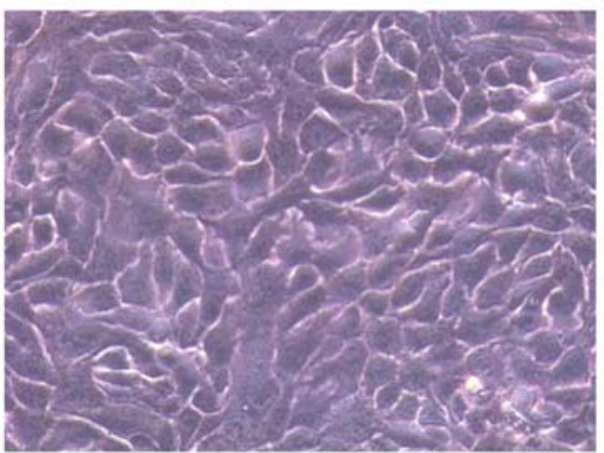

(a)

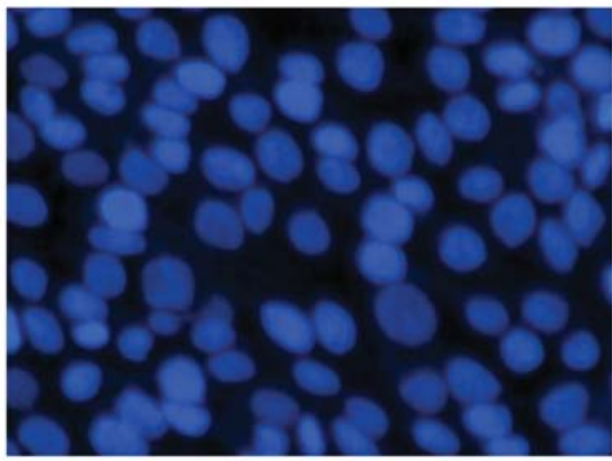

(c)

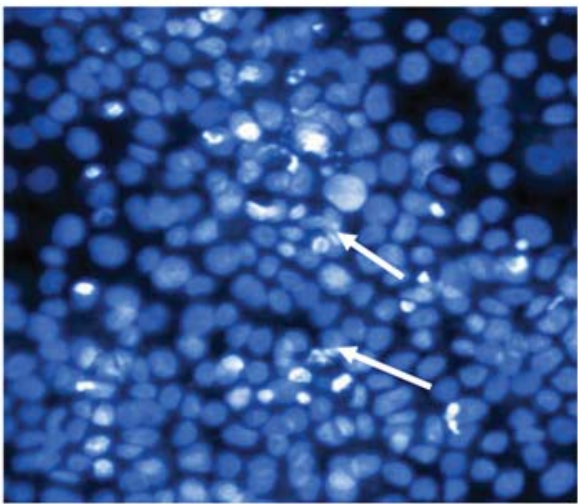

(e)

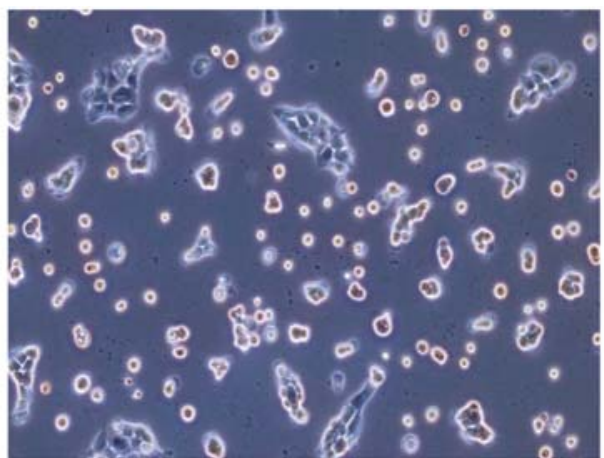

(b)

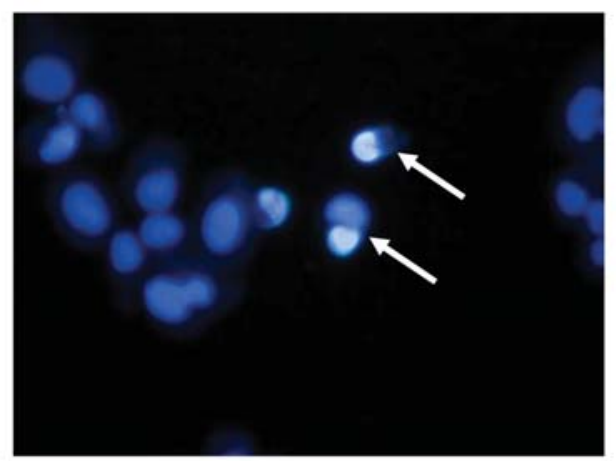

(d)

Figure 2. Effect of realgar on HaCaT morphology as examined by phase contrast microscopy. (a) Normal HaCaT cells. (b) HaCaT cells treated with $10 \mu \mathrm{g} / \mathrm{ml}$ realgar extract for $48 \mathrm{~h}$. (c) Normal HaCaT cells stained with Hoechst 33342. (d and e) HaCaT cells treated with $10 \mu \mathrm{g} / \mathrm{ml}$ realgar for $36 \mathrm{~h}$ and stained with Hoechst 33342. Arrows point to the cells that show chromatin condensation (d) and DNA fragmentation (e).

sation (Fig. 2d) and DNA fragmentation (Fig. 2e), while such apoptotic features were clearly absent in the non-treated cells (Fig. 2c). This morphological observation indicates that realgar is capable of inducing cellular apoptosis to the cultured HaCaT keratinocytes.

DNA fragmentation assay and TUNEL assay. Since DNA cleavage is a hallmark of apoptosis, detection of DNA laddering on electrophoresis was used to confirm the morphological finding regarding the apoptotic action of the realgar extract. As shown in Fig. 3a, DNA laddering was clearly evident by treatment with a higher concentration of realgar for $48 \mathrm{~h}$. In Fig. 3b, the laddering pattern of nucleosome monomer and oligomers was clearly distinguishable after 48 and $72 \mathrm{~h}$ of incubation, though not apparent at $24 \mathrm{~h}$. The appearance of DNA laddering is a strong indicator of cellular DNA fragmentation. In the TUNEL assay, when compared with the control (Fig. 4a), $8 \mu \mathrm{g} / \mathrm{ml}$ realgar was capable of inducing the appearance of apoptotic peaks (Fig. 4b), confirming the occurrence of apoptosis in the HaCaT cells.

Realgar on cell cycle progression. The flow cytometric measurement of PI-stained DNA of the HaCaT cells is shown in Fig. 5. Realgar extract at $10 \mu \mathrm{g} / \mathrm{ml}$ (Fig. 5b) was capable of inducing the sub-G1 phase (apoptotic peak) when compared with the control (Fig. 5a). After treatment with the realgar 


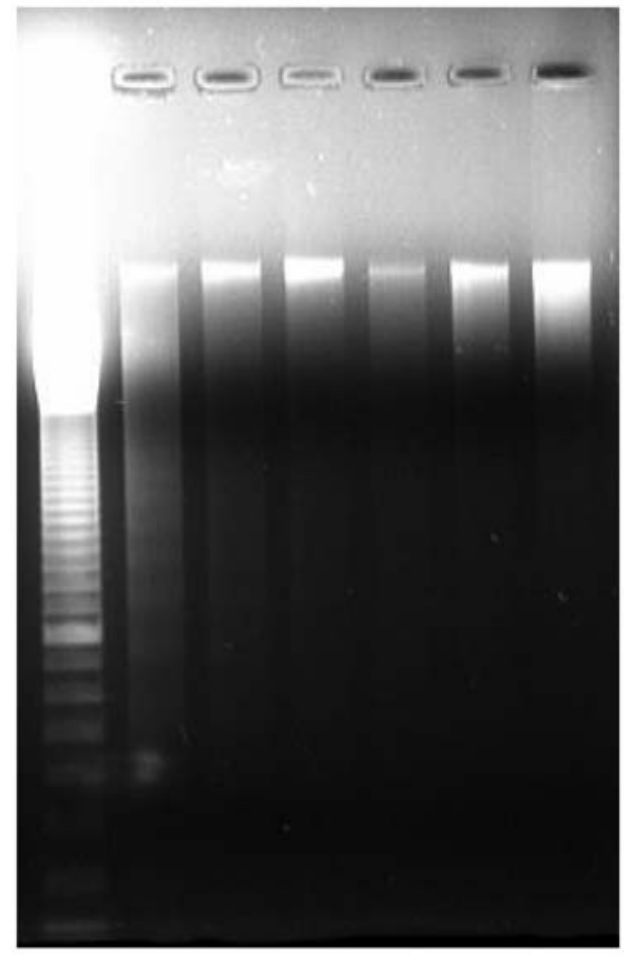

(a)

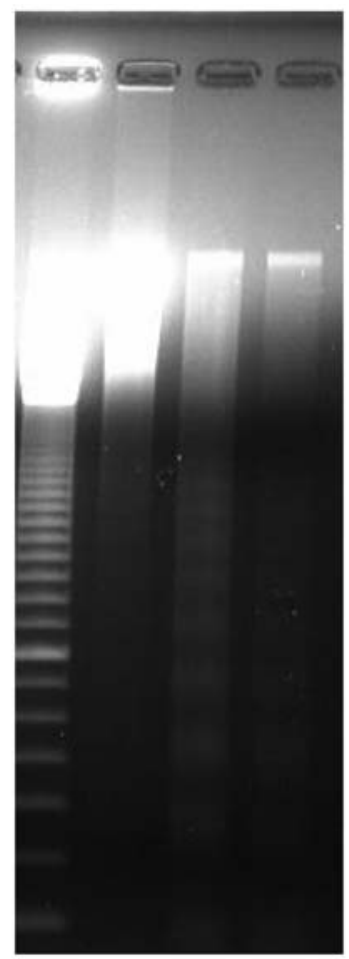

(b)

Figure 3. Action of realgar on DNA fragmentation in HaCaT cells. (a) Lanes 1-7 are 100 base pair marker, realgar at 20, 15, 10, 5 and $2 \mu$ g/ml and cell control, respectively; incubation for $48 \mathrm{~h}$. Note that the laddering pattern was developed at $20 \mu \mathrm{g} / \mathrm{ml}$ realgar treatment. (b) Lanes $1-4$ correspond to $100 \mathrm{base}-$ pair marker, treatment with $20 \mu \mathrm{g} / \mathrm{ml}$ realgar extract for 72,48 and $24 \mathrm{~h}$, respectively. Note that the laddering pattern was clearly observed at $48 \mathrm{~h}$.

extract for $48 \mathrm{~h}$, the amount of cells in sub-G1 phase increased from 0.4 to $44.1 \%$ when the concentration was increased from 2 to $20 \mu \mathrm{g} / \mathrm{ml}$ (Fig. 6a). Also, the sub-G1 population gradually increased from 32.4 to $77.1 \%$ when the incubation time was extended from 24 to $72 \mathrm{~h}$ in the presence of $20 \mu \mathrm{g} / \mathrm{ml}$ realgar extract (Fig. 6b). Moreover, besides the induction of the sub-G1 peak, realgar extract also altered the cell cycle distribution of the cultured $\mathrm{HaCaT}$ cells. After treatment for $48 \mathrm{~h}$ with $20 \mu \mathrm{g} / \mathrm{ml}$ of realgar extract, the percentage of the cells in $\mathrm{G} 1, \mathrm{~S}$ and $\mathrm{G} 2 / \mathrm{M}$ phases changed from $45.8,36.8$ and $17.3 \%$ to $80.5,12.8$ and $6.7 \%$, respectively (Fig. 6c). Furthermore, when exposed to longer time periods, the percentage of cells in the G1 phase increased markedly, while $\mathrm{S}$ and G2/M phases decreased accordingly (Fig. 6d). Taken together, our experimental results demonstrated that realgar extract caused $\mathrm{HaCaT}$ cell arrest at the G1 phase and subsequently induced the cells into apoptosis.

Quantitative analysis of apoptotic cells by annexin V-PI staining. In apoptotic cells, phosphatidylserine (PS) is translocated from the inner to the outer surface of the plasma membrane, and exposure of PS is therefore a useful target for detecting apoptosis (15). The discrimination between apoptotic and necrotic cells could be achieved by quantitatively estimating the relative amount of the annexin $\mathrm{V}$ (which specifically stains to PS) and PI-stained cells in the population. As shown in Fig. 7a, realgar extract significantly accentuated the percentage of apoptotic cells from 7.5 to $87.0 \%$, but the percentage of viable cells was decreased from 80.2 to $4.7 \%$ as the concentration of realgar extract increased from 2 to
$20 \mu \mathrm{g} / \mathrm{ml}$ after $48 \mathrm{~h}$ treatment. Likewise, at $20 \mu \mathrm{g} / \mathrm{ml}$ realgar, the percentage of apoptotic cells increased from 67.3 to $88.1 \%$ as the incubation time was extended from 24 to $72 \mathrm{~h}$ (Fig. 7b). These results illustrated that the apoptotic action of realgar is concentration- and time-dependent.

Western blot analysis. Caspase-3 is the apoptosis-promoting enzyme responsible for cleaving cellular substrates leading to the characteristic cell morphology alterations. Fig. 8 illustrates the effect of realgar extract on the caspase- 3 activation. It is evident that the activity of caspase-3 (19 and $17 \mathrm{kDa}$ ) was augmented by realgar extract. These results demonstrated that the underlying mechanism of the realgar-induced apoptosis in $\mathrm{HaCaT}$ cells involves the cleavage of procaspase- 3 into the activated form of caspase- 3 , leading to the irreversible execution of apoptosis.

\section{Discussion}

It is well recognized that psoriasis is an immune-mediated inflammatory skin disorder, and the immune-abnormality is the fundamental pathogenesis that plays an important role in the initiation, maintenance and progression of this disease. However, when focusing on the psoriatic lesion, a typical psoriatic acanthosis is invariably characterized histologically by hyperproliferation and perturbed differentiation of the epidermal keratinocytes (16). More recently, it has been shown that hyperproliferation of keratinocytes seen in psoriasis is a direct result of diminished apoptosis of this cell type (17). Apoptosis (programmed cell death), is a physiologic cell 


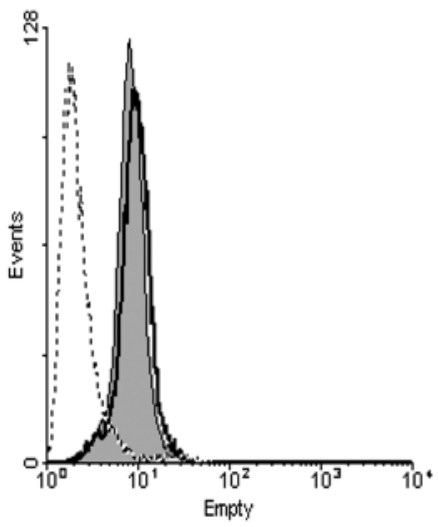

(a)

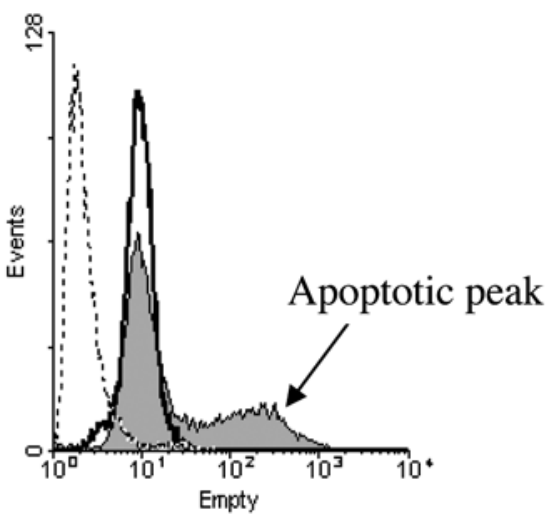

(b)

Figure 4. TUNEL analysis of realgar-mediated apoptosis in HaCaT cells. (a) The cells cultured in the absence of realgar extract. (b) The cells cultured in the presence of $8 \mu \mathrm{g} / \mathrm{ml}$ realgar extract for $36 \mathrm{~h}$. ----, represents control for autofluoresence of cells in the absence of label or enzyme solution. drug-free control incubated with label solution. Gray shading indicates cells incubated with TUNEL reaction mixture containing both label and enzyme solutions.

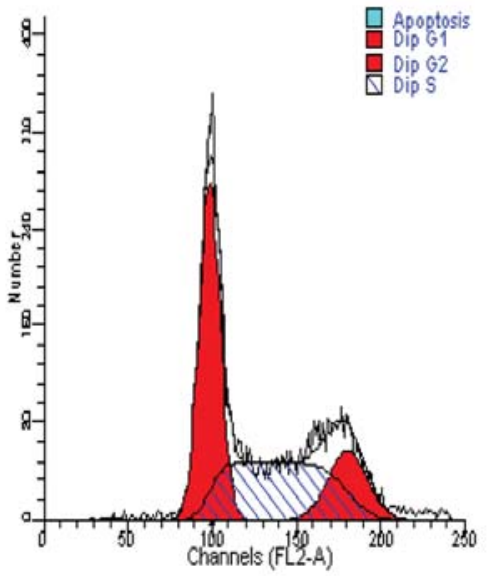

(a)

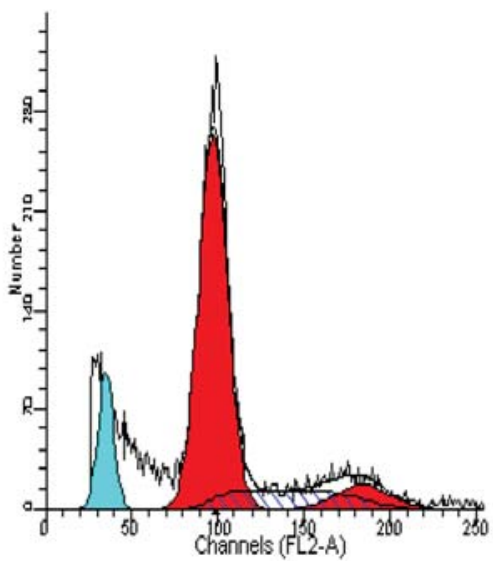

(b)

Figure 5. Flow cytometric analysis of the cell cycle distribution of cultured HaCaT keratinocytes with PI staining. (a) Medium control. (b) The cells treated with $10 \mu \mathrm{g} / \mathrm{ml}$ realgar extract for $48 \mathrm{~h}$. Note the appearance of sub-G1 phase upon the treatment with realgar.

death phenomenon that enables the effective elimination of dysfunctional or senescent cells without evoking a harmful inflammatory response. Because of this unique function, apoptosis plays a crucial role in maintaining homeostasis of continually renewing tissues such as the skin $(18,19)$. Thus, dysfunction or dysregulation of the apoptotic event plays a pivotal role in the initiation, maintenance and development of many hyperproliferative conditions such as cancers as well as psoriasis (20). From the therapeutic perspective, agents capable of inhibiting keratinocyte proliferation and inducing apoptosis are potentially useful in the treatment of psoriasis because a shift of balance in favour of cell death could help to restore the homeostatic control of the hyperproliferative keratinocytes and lead to normalization of the epidermal structure. The fact that several established anti-psoriatic treatments such as dithranol $(21,22)$, PUVA (23) and vitamin $\mathrm{D}_{3}$ analogues $(24,25)$ exert their clinical effect primarily through induction of cellular apoptosis on the epidermal keratinocytes attests to the relevance of this therapeutic strategy in the management of psoriasis.

From a historical perspective, the use of toxic chemicals for disease treatment can be traced back to time antiquity. For example, the use of realgar, an arsenic-containing toxic substance in Chinese materia medica was first recorded in the Shen Nong Ben Cao Jing (Devine Husbandman's Classic of Materia Medica), the first specialist's book on Chinese materia medica written about 2000 years ago. In Chinese medicine practice today, realgar is still prescribed for the treatment of a number of dermatological conditions such as scabies, carbuncles, shingle zoster, psoriasis and enduring wounds (26). The underpinning rationale of utilizing toxic substances such as realgar for therapeutic purpose is said to 'use a poison to attack another poison or to fight against malignant disease' $(3,27)$. However, such a philosophical 


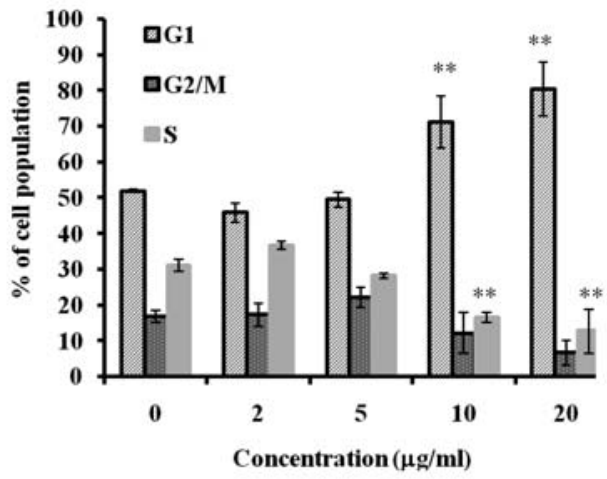

(a)

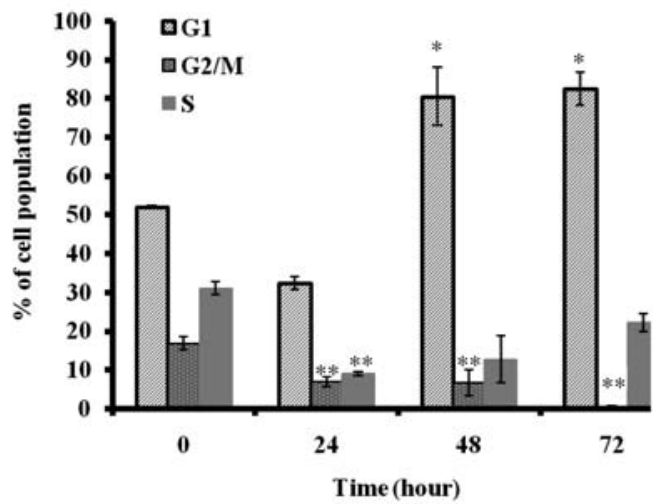

(b)

Figure 6. Bar chart presentations of the $\mathrm{HaCaT}$ keratinocyte cell cycle distribution under the influence of realgar extract. (a) The cells were exposed to different concentrations of realgar extract for $48 \mathrm{~h}$ followed by flow cytometric analysis with PI staining. (b) The cells were treated with $20 \mu \mathrm{g} / \mathrm{ml}$ realgar extract for 24,48 and $72 \mathrm{~h}$, respectively. The values shown are the mean \pm SEM, with $n=3$. ${ }^{*} \mathrm{P}<0.05$ and ${ }^{* *} \mathrm{P}<0.01$ when compared with the medium control.

explanation of the therapeutic rationale cannot sustain the scrutiny of modern scientific community. Illumination of the underlying cellular and molecular mechanisms of action regarding the treatment of psoriasis with realgar is necessary if it be developed into an evidence-based pharmaceutical product in clinical use.

Building on our previous study that realgar extract exhibited potent inhibitory effect on the growth of cultured $\mathrm{HaCaT}$ keratinocytes, the present study aimed at further evaluating the anti-proliferative action of this mineral and elucidating the underlying mechanisms of action for the observed growth inhibitory action. Our experimental results showed that realgar extract time- and concentrationdependently suppressed the growth of HaCaT keratinocyte, a result in congruence with the previous experimental findings (4). It is also noteworthy that in our previous study realgar extract was shown to only cause modest growth inhibition on Hs-68 cells, a line of non-tumorigenic human fibroblast cells, with $\mathrm{IC}_{50}$ value being $48.1 \mu \mathrm{g} / \mathrm{ml}$ when cultured for $48 \mathrm{~h}$. The comparative findings indicate that realgar extract possesses differential cytotoxic profiles on $\mathrm{HaCaT}$ and Hs-68 cells, and it exerts more potent growth inhibition on the more rapidly

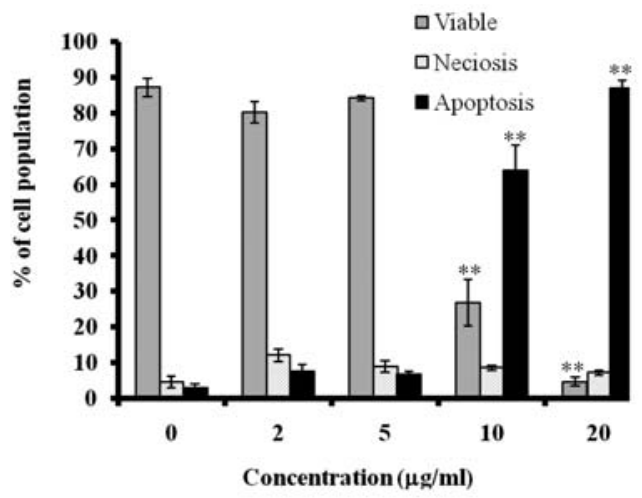

(a)

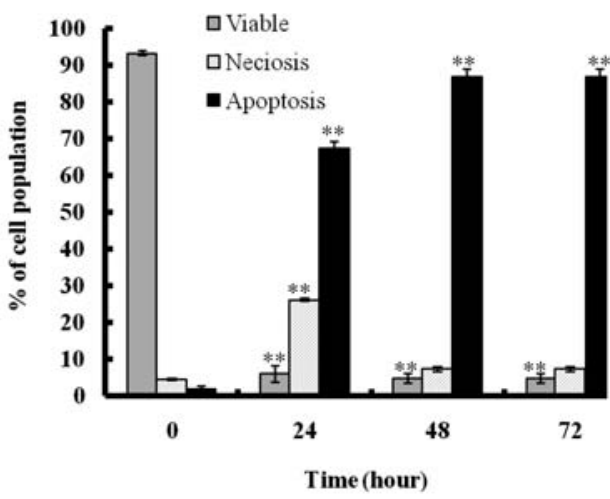

(b)

Figure 7. Bar chart presentations of the distribution of viable, apoptotic and necrotic $\mathrm{HaCaT}$ keratinocytes in the presence of realgar extract as measured by annexin V-PI double staining. (a) Concentration-dependent effect when incubated for $48 \mathrm{~h}$. (b) Time course effect in the presence of $20 \mu \mathrm{g} / \mathrm{ml}$ realgar extract. The values shown represent the mean \pm SEM, with $n=3$. ${ }^{*} \mathrm{P}<0.05$ and ${ }^{* *} \mathrm{P}<0.01$ when compared with the non-treatment control.

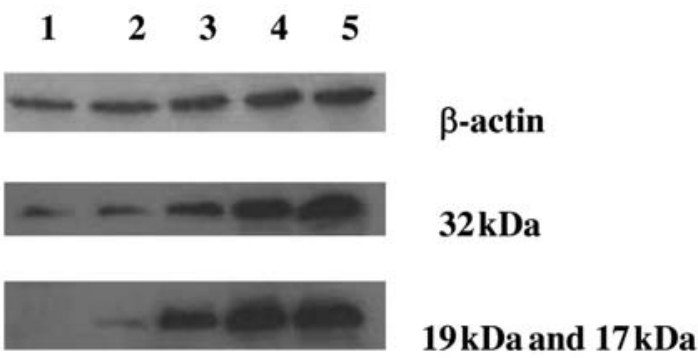

Figure 8. Western blot analysis of the realgar extract-induced expression of caspase-3. Lanes 1-5 correspond to control, 2, 5, 10 and $20 \mu \mathrm{g} / \mathrm{ml}$ of realgar extract, respectively. Note that the band sizes 19 and $17 \mathrm{kDa}$ are the activated caspase- 3 and band size $32 \mathrm{kDa}$ is the procaspase- 3 .

proliferating HaCaT keratinocytes than that of normal Hs-68 fibroblasts.

A good understanding of the underlying cellular and biochemical mechanism for the observed growth inhibitory action would be necessary to place the use of this mineral for psoriasis treatment on a solid scientific basis. As apoptosis and/or necrosis could contribute to growth inhibition of cultured cells, experiments were designed to elucidate whether 
induction of cellular apoptosis indeed underlies realgarmediated growth inhibition. Several assays were employed in our study to detect realgar-induced apoptosis, as no single assay is capable of unambiguously confirming the occurrence of apoptosis. Realgar extract-treated HaCaT cells were found to have hypercondensed nuclei when stained with Hoechst dye followed by observation under the microscope. Realgar extract was able to induce DNA fragmentation as illustrated by gel electrophoresis and the TUNEL method. Cell cycle progression analysis by flow cytometry revealed that realgar extract significantly increased the population of $\mathrm{HaCaT}$ cells in the sub-G1 phase (apoptotic peak) while reducing the number of cells in the G2/M and $S$ phases. Quantitative analysis of apoptotic cells by concomitant annexin V-PI staining also demonstrated that the realgar extract was capable of inducing apoptosis on the HaCaT keratinocytes in a concentration- and time-dependent manner. Finally, the activation of caspase- 3 was detected when the HaCaT keratinocytes were exposed to the realgar extract, indicating unequivocally the occurrence of cellular apoptosis. The above results from different experiments unambiguously confirm that realgar extract induces cellular apoptosis, and this mechanism of action is believed to be responsible for the observed realgar-mediated growth inhibition on $\mathrm{HaCaT}$ human keratinocytes.

The successful identification of realgar as a potent antiproliferative and apoptogenic agent not only helps explain why realgar is effective as a topical treatment for psoriasis, but also renders it a promising candidate for further development into topical therapeutic formulations for psoriasis treatment. However, whether realgar extract is also effective in inhibiting the proliferation of epidermal keratinocytes in psoriasis-relevant animal model has not yet been determined. Further in vivo experiments to evaluate the anti-psoriatic potential of several topical formulations containing realgar on mouse tail test model are currently ongoing in our laboratory.

\section{Acknowledgements}

This study was supported by a Direct Grant from the Chinese University of Hong Kong (Project no. 2030317).

\section{References}

1. Lebwohl M: Psoriasis. Lancet 361: 1197-1204, 2003.

2. Nickoloff BJ and Nestle FO: Recent insights into the immunopathogenesis of psoriasis provide new therapeutic opportunities. J Clin Invest 113: 1664-1675, 2004.

3. Chinese Pharmacopoeia Committee: Pharmacopoeia of China. People's Press, Beijing, 2005.

4. Tse WP, Che CT, Liu K and Lin ZX: Evaluation of the antiproliferative properties of selected psoriasis-treating chinese medicines on cultured HaCaT cells. J Ethnopharmacol 108: 133-141, 2006.

5. Boukamp P, Petrussevska RT, Breitkreutz D, Hornung J, Markham A and Fusenig NE: Normal keratinization in a spontaneously immortalized aneuploid human keratinocyte cell line. J Cell Biol 106: 761-771, 1988.

6. Farkas A, Kemeny L, Szony BJ, Bata-Csorgo Z, Pivarcsi A, Kiss M, Szell M, Koreck A and Dobozy A: Dithranol upregulates IL-10 receptors on the cultured human keratinocyte cell line HaCaT. Inflamm Res 50: 44-49, 2001.

7. Garach-Jehoshua O, Ravid A, Liberman UA and Koren R: 1,25Dihydroxyvitamin D3 increases the growth-promoting activity of autocrine epidermal growth factor receptor ligands in keratinocytes. Endocrinology 140: 713-721, 1999.
8. Thielitz A, Bukowska A, Wolke C, Vetter R, Lendeckel U, Wrenger S, Hashimoto Y, Ansorge S and Gollnik H: Identification of extra- and intracellular alanyl aminopeptidases as new targets to modulate keratinocyte growth and differentiation. Biochem Biophys Res Commun 321: 795-801, 2004.

9. Tse WP, Cheng CHK, Che CT, Zhao M and Lin ZX: Induction of apoptosis underlies the radix rubiae-mediated anti-proliferative action on human epidermal keratinocytes: Implications for psoriasis treatment. Int J Mol Med 20: 663-672, 2007.

10. Gavrieli Y, Sherman Y and Ben-Sasson SA: Identification of programmed cell death in situ via specific labeling of nuclear DNA fragmentation. J Cell Biol 119: 493-501, 1992.

11. Portera-Cailliau C, Sung CH, Nathans J and Adler R: Apoptotic photoreceptor cell death in mouse models of retinitis pigmentosa. Proc Natl Acad Sci USA 91: 974-978, 1994.

12. Nicoletti I, Migliorati G, Pagliacci MC, Grignani F and Riccardi C: A rapid and simple method for measuring thymocyte apoptosis by propidium iodide staining and flow cytometry. J Immunol Methods 139: 271-279, 1991

13. Tounekti O, Belehradek J Jr and Mir LM: Relationships between DNA fragmentation, chromatin condensation, and changes in flow cytometry profiles detected during apoptosis. Exp Cell Res 217: 506-516, 1995.

14. Ernst JD, Yang L, Rosales JL and Broaddus VC: Preparation and characterization of an endogenously fluorescent annexin for detection of apoptotic cells. Anal Biochem 260: 18-23, 1998.

15. Martin SJ, Reutelingsperger CP, McGahon AJ, Rader JA, van Schie RC, LaFace DM and Green DR: Early redistribution of plasma membrane phosphatidylserine is a general feature of apoptosis regardless of the initiating stimulus: inhibition by overexpression of Bcl-2 and Abl. J Exp Med 182: 1545-1556, 1995.

16. Camisa C: Handbook of Psoriasis. Blackwell Science, Malden, 1998.

17. Kawashima K, Doi H, Ito Y, Shibata MA, Yoshinaka R and Otsuki Y: Evaluation of cell death and proliferation in psoriatic epidermis. J Dermatol Sci 35: 207-214, 2004.

18. Bianchi L, Farrace MG, Nini G and Piacentini M: Abnormal Bcl-2 and 'tissue' transglutaminase expression in psoriatic skin. J Invest Dermatol 103: 829-833, 1994.

19. Reed JC: Bcl-2 family proteins. Oncogene 17: 3225-3236, 1998.

20. Fadeel B, Gleiss B, Hogstrand K, Chandra J, Wiedmer T, Sims PJ, Henter JI, Orrenius S and Samali A: Phosphatidylserine exposure during apoptosis is a cell-type-specific event and does not correlate with plasma membrane phospholipid scramblase expression. Biochem Biophys Res Commun 266: 504-511, 1999.

21. Kanerva L: Electron microscopy of the effects of dithranol on healthy and on psoriatic skin. Am J Dermatopathol 12: 51-62, 1990.

22. McGill A, Frank A, Emmett N, Turnbull DM, Birch-Machin MA and Reynolds NJ: The anti-psoriatic drug anthralin accumulates in keratinocyte mitochondria, dissipates mitochondrial membrane potential, and induces apoptosis through a pathway dependent on respiratory competent mitochondria. FASEB J 19: 1012-1014, 2005.

23. Laporte M, Galand P, Fokan D, de Graef C and Heenen M: Apoptosis in established and healing psoriasis. Dermatology 200: 314-316, 2000.

24. Benassi L, Ottani D, Fantini F, Marconi A, Chiodino C Giannetti $A$ and Pincelli C: 1,25-Dihydroxyvitamin $\mathrm{D}_{3}$, transforming growth factor $\mathrm{B} 1$, calcium, and ultraviolet $\mathrm{B}$ radiation induce apoptosis in cultured human keratinocytes. J Invest Dermatol 109: 276-282, 1997.

25. Bektas M, Orfanos CE and Geilen CC: Different vitamin D analogues induce sphingomyelin hydrolysis and apoptosis in the human keratinocyte cell line HaCaT. Cell Mol Biol 46: 111-119, 2000.

26. Jiangsu New Medical College: Encyclopedia of Chinese Materia Medica. Shanghai Science and Technology Press, Shanghai, pp2337-2339, 1986.

27. Evens AM, Tallman MS and Gartenhaus RB: The potential of arsenic trioxide in the treatment of malignant disease: past, present and future. Leuk Res 28: 891-900, 2004. 